\title{
Effects of cortical lesions on middle-latency auditory evoked responses (MLR)
}

\author{
Paul Kileny *, Daniel Paccioretti ** and A.F. Wilson ** \\ * Department of Otolaryngology, Head and Neck Surgery, University of Michigan Medical Center, Ann Arber. MI 48109 (U.S.A.), \\ and ** Glenrose Rehabilitation Hospital, Edmonton, Alberta (Canada)
}

(Accepted for publication: 9 June, 1986)

\begin{abstract}
Summary Middle-latency auditory evoked responses (MLRs) were recorded simultaneously at 3 or 4 electrode locations in the coronal plane in 5 normal subjects, 11 patients with temporal lobe lesions and in 5 patients with cortical lesions not involving the temporal lobes. In patients with unilateral temporal lobe lesions, the amplitude of $\mathrm{Pa}$ and hence that of the $\mathrm{Na}$ - $\mathrm{Pa}$ complex was reduced over the involved hemisphere but remained intact over the contralateral hemisphere. No MLR asymmetries were demonstrated in patients with cortical lesions that did not affect the temporal lobes or in 2 cases with unilateral anterior temporal lobectomy. The latency of wave $\mathrm{V}$ of the auditory brain-stem response was within normal limits in the majority of the patients studied regardless of the site of their cortical lesion.
\end{abstract}

Key words: middle-latency auditory evoked responses; cortical lesions; CT scans; coronal distribution; ipsilateral, contralateral hemisphere

The middle-latency components of the auditory evoked response (MLR) occur within a latency range of $100 \mathrm{msec}$ following the presentation of an effective auditory stimulus. Geisler et al. (1957) were the first to describe the MLR as 'an early response with an onset latency of about $20 \mathrm{msec}$ ' characterized by a vertex-positive peak with a latency of about $30 \mathrm{msec}$. While the scalp distribution of the MLR is widespread, it has been reported to be most prominent over fronto-central regions (Picton et al. 1974; Özdamar and Kraus 1983). With monaural stimulation, the responses recorded between vertex $(\mathrm{Cz})$ and ipsilateral or contralateral earlobes were reported to be symmetrical (Peters and Mendel 1974). The configuration of the recorded MLR depends upon the characteristics (cut-off frequencies, filter slopes) of the

Correspondence to: Dr. P. Kileny, Dept. of Otolaryngology, Head and Neck Surgery, University of Michigan Hospitals, A. Alfred Taubman Health Care Center, TC-1904-0312, 1500 E. Medical Center Drive, Ann Arbor, MI 48109-0312, U.S.A.
EEG filter (Scherg 1982; Sprague and Thornton 1982; Kileny 1983). Considerable distortion may be introduced by high-pass filtering when utilizing relatively steep analogue filters. With a relatively wide input filter setting (i.e., $5-1500 \mathrm{~Hz}$ ), one can simultaneously record both the early brain-stem components of the auditory evoked response and the MLR components (Özdamar et al. 1982; Kileny 1983). The most prominent, robust and stable component in adults is the vertex-positive peak usually labeled $\mathrm{Pa}$ (peak latency $25-30 \mathrm{msec}$ ).

Controversy surrounds the identity of the generator sources of the MLR. While there is some overlapping of myogenic and neurogenic activity during the $100 \mathrm{msec}$ poststimulus latency range, the MLR is basically a neurogenic auditory evoked response which remains unaffected following the administration of neuromuscular blocking agents (Harker et al. 1977; Kileny 1983; Kileny et al. 1983). Responses have been recorded from the exposed human cortex within the latency range associated with the scalp-recorded MLR (Heath 
and Galbraith 1966; Celesia et al. 1968; Pulletti and Celesia 1970). These have been considered to be primary auditory responses and were elicited by both ipsilateral and contralateral auditory stimulation. Their cortical distribution was limited to the posterior part of the superior temporal gyrus and the parietal and frontal operculum. Cortical sensory responses recorded in this latency range are as a rule considered to be mediated by the specific lemniscal sensory pathways and specific thalamic nuclei (Brazier 1972). Picton et al. (1974) listed several possible neural generator sources for the MLR: thalamus, association cortex in frontal, parietal and temporal lobes.

A recent study by Woods and Clayworth (1985) revealed differences between the scalp distributions and hemisphere-ear interactions of the $\mathrm{Na}$ and Pa components of the MLR in normal subjects. While the $\mathrm{Pa}$ component exhibited the same baseline-to-peak absolute amplitude when recorded over the ipsilateral and the contralateral hemisphere, the Na component exhibited reduced latencies and increased amplitudes over the hemisphere contralateral to the stimulated ear.

There have been conflicting reports in the literature concerning the effects of temporal lobe lesions on the MLR. Parving et al. (1980) reported on a patient with auditory agnosia and documented bilateral temporal lobe lesions who exhibited normal MLRs. Özdamar et al. (1982) reported on a patient who also presented with bilateral temporal lobe lesions, inconsistent awareness of sound and impaired pure-tone hearing sensitivity who presented with abnormal MLR wave forms: $\mathrm{Pa}$ was absent bilaterally. Based on their respective results, the two groups of investigators arrived at opposite conclusions regarding the role of the primary auditory cortex in the generation of the MLR.

In a recent study, Kraus et al. (1982) reported on the effects of temporal lobe lesions on the coronal scalp distribution of the MLR in 24 patients. MLRs were recorded simultaneously at the vertex and over the right and the left hemispheres slightly above the sylvian fissure in the coronal plane. In contrast to normal subjects in whom the amplitude of $\mathrm{Pa}$ was largest at the vertex and symmetrical at the supra-sylvian electrodes, pa- tients with confirmed temporal lobe lesions exhibited reduced or absent $\mathrm{Pa}$ peaks over the damaged hemisphere. They concluded that the vertex-recorded MLR reflects contributions from symmetrical bilateral generators. Under normal circumstances, their electrical activity is summed at the vertex. With a unilateral lesion the vertex response would be diminished due to a reduction of the contribution originating from the affected side.

The present study was prompted by the results reported by Kraus et al. (1982). While their study was unique in that it consistently correlated welldefined MLR abnormalities with documented brain lesions in humans, it did not address two important questions:

(1) What, if any, are the effects of other localized cortical lesions not involving the temporal lobes on the configuration of the MLR?

(2) Is there an interaction between the site of lesion and the test-ear (right or left), i.e., is the effect described by Kraus et al. (1982) more pronounced when stimulating the ear ipsilateral to the lesion or when stimulating the ear contralateral to the lesion?

\section{Materials and Methods}

Sixteen patients aged 21-71 years with a variety of cortical lesions (Table I) resulting mainly from cerebrovascular accidents, 5 normal subjects and 2 patients with right anterior lobectomies were included in this study. All patients were first assessed by conventional behavioral audiometry techniques (pure-tones, speech and immittance). They were also assessed by a speech-language pathologist and a psychologist to determine speech, language and cognitive skills. Table I lists the following information on the 16 patients with cortical lesions: site of lesion determined from CT scans, etiology, hearing status, the status of the auditory brain-stem response (ABR), speech-language and cognitive function and the audiological evaluations.

The evoked potential studies were performed $2-4$ weeks following the onset of the traumatic or vascular brain injury. Neuro-electrical activity was 
TABLE I

\begin{tabular}{|c|c|c|c|c|c|c|c|}
\hline Patient no. & Age & Sex & Site of lesion & Etiology & Hearing & $\begin{array}{l}\text { ABR wave } \\
\text { V latency }\end{array}$ & $\begin{array}{l}\text { Speech-language and } \\
\text { cognitive function }\end{array}$ \\
\hline \multicolumn{8}{|c|}{ Patients with temporal lobe involvement } \\
\hline 1 & 49 & $\mathbf{M}$ & (R) Fronto-temporal & Trauma & $\begin{array}{l}\text { Mild-mod. HF } \\
\text { Sensorineural } \\
\text { Bilateral }\end{array}$ & WNL & $\begin{array}{l}\text { Mild dysphonia, impaired } \\
\text { memory }\end{array}$ \\
\hline 2 & 70 & $\mathrm{~F}$ & (L) Fronto-temporal & Infarct & $\begin{array}{l}\text { Mild high freq. } \\
\text { Sensorineural } \\
\text { Bilateral }\end{array}$ & WNL & Mild apraxia \\
\hline 3 & 53 & F & (R) Fronto-temporal & Infarct & $\begin{array}{l}\text { Mild-moderate } \\
\text { Sensorineural } \\
\text { Bilateral }\end{array}$ & WNL & $\begin{array}{l}\text { Mixed aphasia. } \\
\text { decreased attention }\end{array}$ \\
\hline 4 & 37 & M & $\begin{array}{l}\text { (L) Fronto-temporal } \\
\text { parietal }\end{array}$ & Infaret & $\begin{array}{l}\text { Mild-severe } \mathrm{HF} \\
\text { Sensorineural } \\
\text { Bilateral }\end{array}$ & WNL & $\begin{array}{l}\text { Impaired expressive } \\
\text { language }\end{array}$ \\
\hline 5 & 35 & M & (R) Temporal parietal & Infarct & $\begin{array}{l}\text { Mild HF } \\
\text { Sensorineural } \\
\text { Bilateral }\end{array}$ & WNL & Normal speech-language \\
\hline 6 & 70 & $\mathrm{~F}$ & (R) Temporal parietal & Infarct & $\begin{array}{l}\text { Mild HF } \\
\text { Sensorineural }\end{array}$ & WNL & $\begin{array}{l}\text { Functional speech-language, } \\
\text { impaired memory and attention }\end{array}$ \\
\hline 7 & 44 & $\mathrm{~F}$ & (L) Temporal parietal & Infarct & $\begin{array}{l}\text { Mild-moderate HF } \\
\text { Sensorineural }\end{array}$ & WNL & $\begin{array}{l}\text { Non-fluent aphasia, } \\
\text { slow cognitive processing }\end{array}$ \\
\hline 8 & 62 & M & (L) Temporal parietal & Infarct & $\begin{array}{l}\text { Mild-moderate HF } \\
\text { Sensorineural }\end{array}$ & WNL & $\begin{array}{l}\text { Severe receptive-expressive } \\
\text { aphasia and dyspraxia }\end{array}$ \\
\hline 9 & 71 & $\mathbf{F}$ & (L) Deep temporal & Infarct & $\begin{array}{l}\text { Mild-profound } \mathrm{HF} \\
\text { Sensorineural } \\
\text { Bilateral }\end{array}$ & WNL & $\begin{array}{l}\text { Mild aphasia, impaired } \\
\text { memory, attention and } \\
\text { cognitive insight }\end{array}$ \\
\hline 10 & 61 & $F$ & (L) Fronto-temporal & Infarct & WNL & WNL & $\begin{array}{l}\text { Moderate-severe verbal } \\
\text { dyspraxia, impaired memory }\end{array}$ \\
\hline 11 & 56 & M & (L) Fronto-temporal & Infarct & $\begin{array}{l}\text { Mild-moderate } \\
\text { HF sensorineural }\end{array}$ & WNL & $\begin{array}{l}\text { Receptive and expressive } \\
\text { aphasia, impaired memory } \\
\text { and cognitive insight }\end{array}$ \\
\hline \multicolumn{8}{|c|}{ Patients with lesions not affecting temporal lobes } \\
\hline 1 & 21 & $\mathrm{M}$ & (L) Frontal & Trauma & $\begin{array}{l}\text { Mild-moderate } \\
\text { HF sensorineural } \\
\text { Bilateral }\end{array}$ & WNL & Aphonia anxiety \\
\hline 2 & 39 & F & (L) Fronto-parietal & Infarct & WNL & WNL & $\begin{array}{l}\text { Apraxia and expressive } \\
\text { aphasia }\end{array}$ \\
\hline 3 & 66 & $\mathbf{M}$ & (L) Posterior parietal & Infarct & $\begin{array}{l}\text { Mild-severe } \\
\text { Sensorineural } \\
\text { Bilateral }\end{array}$ & & $\begin{array}{l}\text { Receptive and expressive } \\
\text { aphasia, impaired memory } \\
\text { and cognitive insight }\end{array}$ \\
\hline 4 & 67 & M & (L) Posterior parietal & Infarct & $\begin{array}{l}\text { Mild-moderate } \\
\text { Sensorineural } \\
\text { Bilateral }\end{array}$ & WNL & Mild apraxia \\
\hline 5 & 17 & M & (L) Fronto-parietal & Trauma & WNL & WNL & Functional speech deficit \\
\hline
\end{tabular}

recorded simultaneously at 3 or 4 scalp locations in the coronal plane as follows $(10 / 20$ electrode system, Jasper 1958): vertex $(\mathrm{Cz})$; right and left parietal electrodes just above the sylvian fissure (C6 and C5 respectively); and in some cases below the sylvian fissure over the temporal lobe of the affected side (T3 and T4 respectively). All active electrodes were referenced to common linked earlobe electrodes.

Middle-latency auditory evoked responses were 
elicited by $65 \mathrm{~dB}$ SL broad-band clicks alternated in polarity presented monaurally at a rate of 9.1-9.7/sec by earphones encased in supra-aural cushions. During testing the patients were awake and resting comfortably in a recliner. The EEG was differentially amplified $(\times 40,000)$ and bandpass filtered $(5-1500 \mathrm{~Hz}, 12 \mathrm{~dB} / \mathrm{oct})$. Each response consisted of the summation of 2000 accepted sweeps (the grand average of 2 responses each consisting of 1000 accepted sweeps) with a duration of 102.4 msec. Responses were obtained from each patient for both right ear and left ear stimulation. Each stimulus condition resulted in 3-4 responses obtained simultaneously from the electrode locations mentioned above. The following measurements were made for each response utilizing the cursors of the signal averager: latencies of wave $\mathrm{V}, \mathrm{Na}, \mathrm{Pa}$, the $\mathrm{Na}$-Pa peak-to-peak amplitudes and the absolute amplitudes of the $\mathrm{Na}$ and $\mathrm{Pa}$ peaks. The data were analyzed statistically by means of an analysis of variance and covariance with repeated measures.

\section{Results}

Fig. 1 illustrates the coronal distribution of the MLR in 1 of the 5 normal control subjects. As described by Kraus et al. (1982) Pa amplitude was largest at the vertex and symmetrically reduced at the supra-temporal electrode locations (C5, C6). In this example, a recording was also made below the projection of the sylvian fissure over the left temporal lobe (T3). The response recorded at this site exhibited a further reduction in $\mathrm{Pa}$ amplitude, a slight delay in its latency and a general broadening of the peak.

Table II lists mean values and standard deviations for MLR peak amplitudes and latencies for

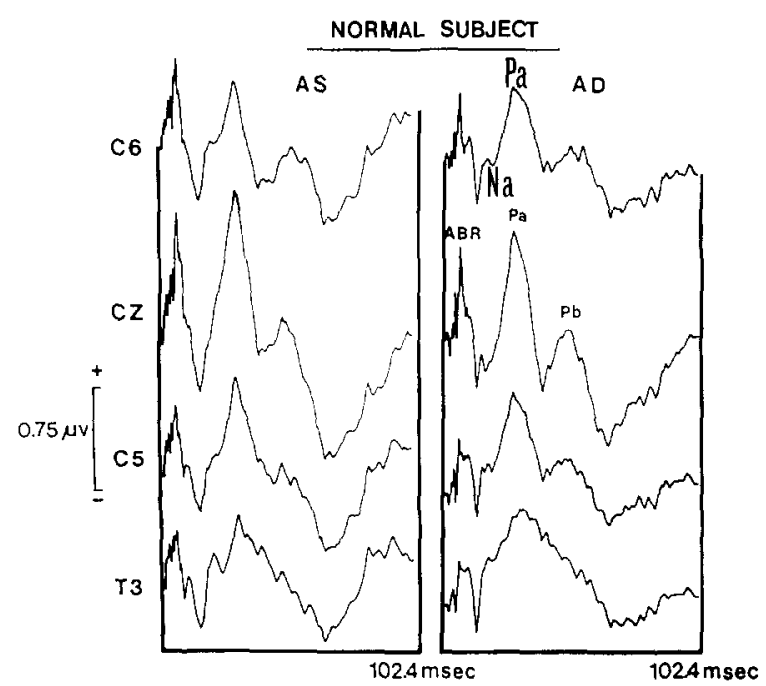

Fig. 1. Central coronal distribution of MLR in a normal subject. AS, left ear; AD, right ear.

the 5 normal subjects. These mean values are listed for the left and the right hemispheres (C5 and C6) separately, with the results of left ear and right ear stimulation pooled for each hemisphere. As illustrated in this table, the values obtained from the left and the right hemispheres were symmetrical and with about the same degree of variability.

Table III lists mean amplitude and latency values along with their respective standard deviations for the patients with brain lesions not affecting the temporal lobes. For these patients as well as for the patients presenting with temporal lobe lesions, the data were divided as follows: the amplitude and latency values recorded from the involved hemisphere (CI) and those recorded from the non-involved hemisphere (CC) were listed separately with respect to ipsilateral and contralateral

TABLE II

MLR latencies and amplitudes: normal subjects. Means/standard deviations.

\begin{tabular}{lllllll}
\hline & & \multicolumn{2}{l}{ Amplitudes $(\mu \mathrm{V})$} & & \multicolumn{2}{l}{ Latencies (msec) } \\
\cline { 3 - 4 } \cline { 6 - 7 } & $\mathrm{Na}-\mathrm{Pa}$ & $\mathrm{Na}$ & $\mathrm{Pa}$ & $\mathrm{Na}$ & $\mathrm{Pa}$ \\
\hline Left (C5) & $1.26 / 0.330$ & $0.310 / 0.202$ & $0.955 / 0.477$ & & $14.91 / 2.20$ & $27.67 / 2.13$ \\
Right (C6) & $1.27 / 0.320$ & $0.343 / 0.201$ & $0.935 / 0.490$ & & $14.91 / 2.20$ & $27.81 / 2.20$ \\
\hline
\end{tabular}


TABLE III

Patients with brain lesions not affecting the temporal lobes. Means and standard deviations.

\begin{tabular}{llllll}
\hline & \multicolumn{2}{l}{ Amplitudes $(\mu \mathrm{V})$} & & \multicolumn{2}{l}{ Latencies (msec) } \\
\cline { 2 - 4 } & $\mathrm{Na}-\mathrm{Pa}$ & $\mathrm{Na}$ & $\mathrm{Pa}$ & $\mathrm{Na}$ & $\mathrm{Pa}$ \\
\hline AICI & $1.15 / 0.49$ & $0.321 / 0.250$ & $0.829 / 0.551$ & $14.82 / 2.20$ & $29.50 / 3.42$ \\
AICC & $1.19 / 0.60$ & $0.360 / 0.274$ & $0.830 / 0.612$ & $14.84 / 2.27$ & $29.52 / 3.27$ \\
ACCI & $1.12 / 0.50$ & $0.378 / 0.311$ & $0.742 / 0.623$ & $14.64 / 2.66$ & $28.46 / 3.58$ \\
ACCC & $1.14 / 0.49$ & $0.329 / 0.323$ & $0.811 / 0.589$ & $14.66 / 2.69$ & $28.52 / 3.58$ \\
\hline
\end{tabular}

ear stimulation (re., site of lesion). Thus, for instance, 'AICI' designates values recorded from the hemisphere containing the lesion (CI) when stimulating the ear ipsilateral to the site of lesion (AI). 'AICC' designates values recorded from the contralateral intact hemisphere following stimulation of the ear ipsilateral to the lesion. 'ACCI' designates values recorded from the hemisphere containing the lesion following contralateral ear stimulation. And finally, 'ACCC' designates values recorded from the contralateral intact hemisphere following stimulation of the ear contralateral to the site of lesion. As in the case of the normal subjects whose data are listed in Table II, the peak-to-peak amplitudes, $\mathrm{Na}$ and $\mathrm{Pa}$ peak amplitudes as well as $\mathrm{Na}$ and $\mathrm{Pa}$ latencies, were symmetrical across hemispheres and stimulus conditions. The order of magnitude of the values listed in Table III was similar to those listed in Table II.

Table IV lists the mean values and standard deviations obtained from MLRs recorded from the patients presenting with temporal lobe lesions. While the latency values were symmetrical and similar to those listed for the normal subjects and the patients with cortical lesions not affecting the temporal lobes, the amplitude values were overall reduced for these patients. This is particularly true for measurements obtained over the hemisphere containing the lesion (CI) both with ipsilateral (AI) and contralateral (AC) ear stimulation. The difference between amplitude values recorded over the hemisphere containing the temporal lobe lesion and those recorded over the contralateral intact hemisphere appears to be most pronounced for the Na-Pa peak-to-peak amplitude measurements and for the absolute amplitude of $\mathrm{Pa}$. At the bottom of this table, values obtained with ipsilateral and contralateral ear stimulation have been pooled for both the involved and uninvolved hemispheres respectively. These data exhibited a clear asymmetry of the Na-Pa peak-to-peak amplitude and absolute $\mathrm{Pa}$ amplitude with a marked reduction of these values when recorded over the involved hemisphere.

The data obtained from the 2 patient groups were treated statistically using an analysis of variance and covariance with repeated measures. The

TABLE IV

Temporal lobe patients. Means/standard deviations

\begin{tabular}{|c|c|c|c|c|c|}
\hline & \multicolumn{3}{|c|}{ Amplitudes $(\mu \mathrm{V})$} & \multicolumn{2}{|c|}{ Latencies (msec) } \\
\hline & $\mathrm{Na}-\mathrm{Pa}$ & $\mathrm{Na}$ & $\mathrm{Pa}$ & $\mathrm{Na}$ & $\mathrm{Pa}$ \\
\hline AICI & $0.474 / 0.171$ & $0.162 / 0.150$ & $0.312 / 0.192$ & $14.87 / 1.76$ & $29.97 / 2.77$ \\
\hline AICC & $0.841 / 0.186$ & $0.199 / 0.137$ & $0.642 / 0.235$ & $15.05 / 1.94$ & $29.66 / 2.65$ \\
\hline $\mathrm{ACCI}$ & $0.627 / 0.214$ & $0.237 / 0.129$ & $0.390 / 0.289$ & $14.36 / 1.70$ & $29.95 / 3.08$ \\
\hline $\mathrm{ACCC}$ & $0.874 / 0.241$ & $0.255 / 0.170$ & $0.619 / 0.313$ & $14.40 / 1.76$ & $30.22 / 3.25$ \\
\hline $\mathrm{CI}(\mathrm{AI}$ and $\mathrm{AC})$ & $0.550 / 0.192$ & $0.199 / 0.144$ & $0.351 / 0.240$ & $14.61 / 1.73$ & $29.96 / 2.92$ \\
\hline$C C(A I$ and $A C)$ & $0.857 / 0.213$ & $0.227 / 0.153$ & $0.630 / 0.274$ & $14.72 / 1.85$ & $29.94 / 2.95$ \\
\hline
\end{tabular}


statistical analysis including the $\mathrm{Na}-\mathrm{Pa}$ peak-topeak amplitude measures from the temporal lobe and non-temporal patients showed a significant difference between the 2 patient groups ( $F=9.0$; $d f=1,13 ; P<0.01$ ).

In the temporal lobe patient group $\mathrm{Na}-\mathrm{Pa}$ amplitudes from the involved hemisphere were compared to those from the uninvolved hemispheres (CI vs. CC) with ipsilateral and contralateral ear stimulation (with respect to site of lesion; AI vs. $A C)$. The interaction between the stimulated ear and the recording site was also analyzed. The results of this analysis indicated significantly reduced $\mathrm{Na}-\mathrm{Pa}$ amplitudes recorded over the involved hemisphere $(F=9 ; d f=1,9 ; \quad P<0.01)$. The interaction between stimulated ear and recording site was not significant. Similarly, a comparison of $\mathrm{Na}-\mathrm{Pa}$ amplitudes obtained following ipsilateral (AI) and contralateral (AC) ear stimulation with respect to site of lesion was not significant either.

In order to determine whether the absolute (baseline-to-peak) amplitudes of $\mathrm{Pa}$ and $\mathrm{Na}$ respectively were or were not affected differentially by the presence of a temporal lobe lesion, separate analyses of variance and covariance were performed for each of these parameters in the temporal lobe lesion group. Only one of the comparisons reached statistical significance: the absolute amplitude of $\mathrm{Pa}$ was significantly reduced over the involved hemisphere $(F=11 ; d f=1,10 ; P<$ $0.007)$. The absolute amplitude of $\mathrm{Na}$ was not affected likewise.

The following case studies illustrate the effects of various cortical lesions - temporal and nontemporal on the distribution and configuration of the MLR.

\section{Patient 1 - unilateral right temporal lobe involve- ment}

A 35-year-old male was admitted to the hospital with a sudden onset of left hemiparesis. At the time of admission he related a long history of migraine headaches. He was diagnosed as having sustained a right middle cerebral artery infarction involving the right temporal and parietal lobes. This resulted in a compression of midline structures from right to left and in the compression of the right lateral ventricle. This patient's CT scans are illustrated in Fig. 2. In this and subsequent cases presented in this paper, the $\mathrm{CT}$ scans consist of transverse (horizontal) cuts in a plane parallel to a line drawn between the outer canthi and the external acoustic meati. The CT scans illustrated in Fig. 2 demonstrate widespread hypodensity involving the right hemisphere affecting the superior temporal gyrus including Brodmann's area 41 , the middle temporal gyrus, the inferior temporal gyrus (both anterior and posterior aspects). Additional structures affected in this patient were the insula, the pre-central and post-central gyri, the supramarginal gyrus, the angular gyrus as well as the inferior frontal gyrus (Gado et al. 1979). An audiological evaluation revealed a mild bilateral high frequency hearing loss with normal pure-tone thresholds through $2000 \mathrm{~Hz}$. This hearing impairment was reported to have existed before the onset of the neurological problems. A speech-language pathology assessment indicated normal receptive and expressive language skills. Fig. 3 illustrates MLRs recorded from this patient. In this and subsequent figures, the left-hand column consists of responses elicited by left ear stimulation and the right-hand column consists of responses elicited by right ear stimulation. The top traces are responses recorded over the right hemisphere, the middle traces are responses recorded at the vertex and the bottom traces are responses over the left hemisphere. In this case, the responses recorded at the vertex and over the left hemisphere have a normal appearance. It is, however, clear that unlike in the case of the normal subject (Fig. 1) the amplitude of the vertex-recorded response does not exceed the amplitude of the response recorded over the left hemisphere. With both left and right ear stimulation the response recorded over the right side consisted mostly of the brain-stem component. With right ear stimulation there was some reduced activity in the latency range commonly associated with $\mathrm{Pa}$, however, none such is noted with left ear stimulation.

Patient 2 - unilateral left temporal lobe lesion

A 61-year-old male patient sustained a left middle cerebral artery infarction involving the temporal and parietal lobes around the sylvian 

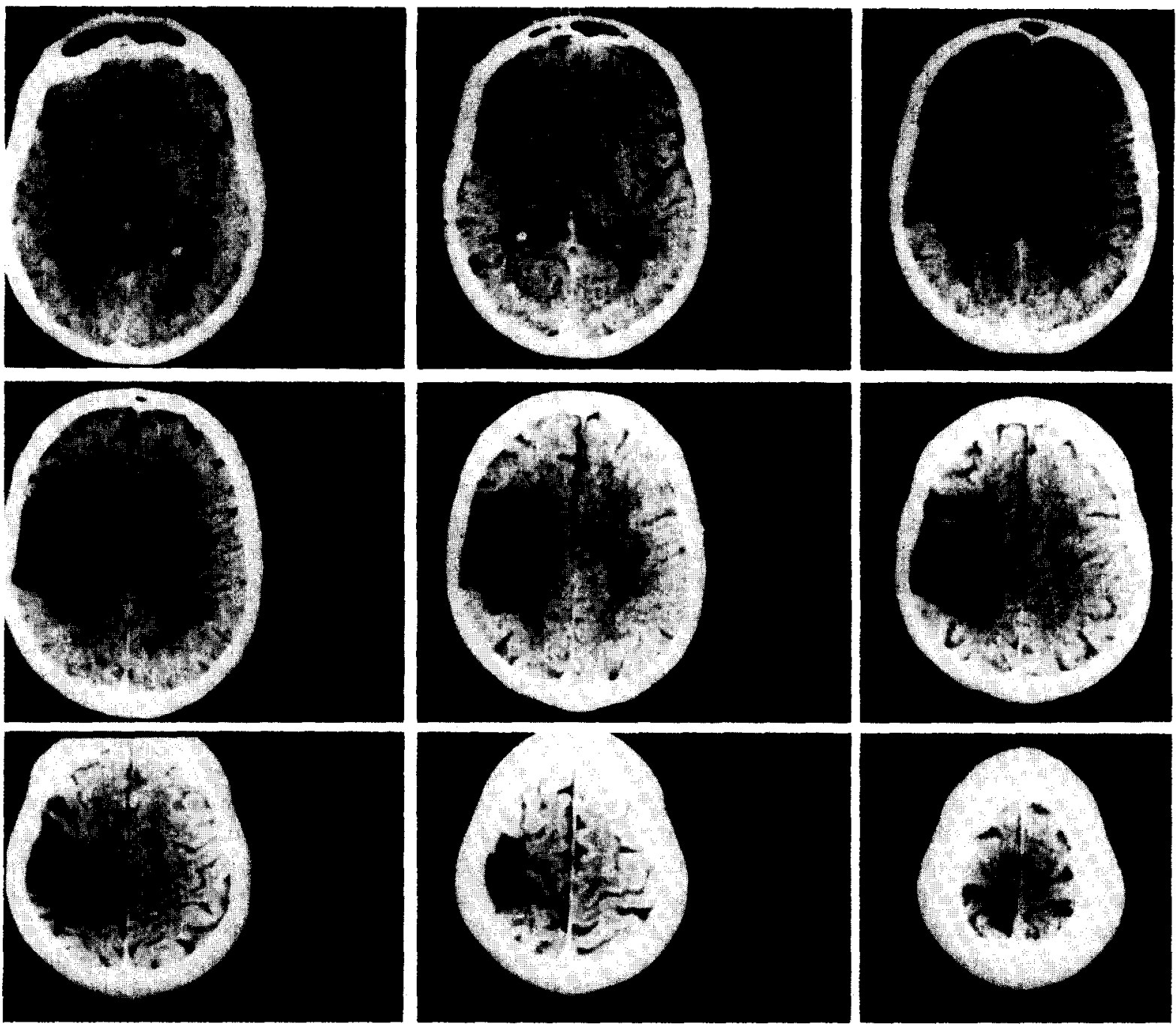

Fig. 2. CT scans of patient 1 demonstrating a right temporo-parietal lesion.

\section{M, 35, RIGHT TEMPORO-PARIETAL LESION}

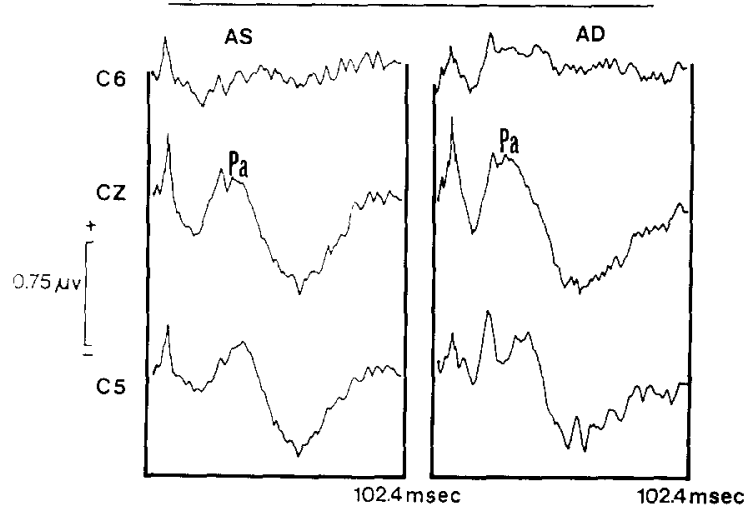

fissure. The temporal lobe lesion included the inferior, middle and superior temporal gyri with both areas 41 and 42 affected. Fig. 4 illustrates this patient's CT scans characterized by a large area of hypodensity involving the left temporal and parietal lobes around the sylvian fissure. Audiology and speech-language assessments revealed a mild to moderate bilateral high frequency

Fig. 3. Coronal distribution of MLR for patient 1 demonstrating a reduction of the Na-Pa amplitude over the right hemisphere (C6). 

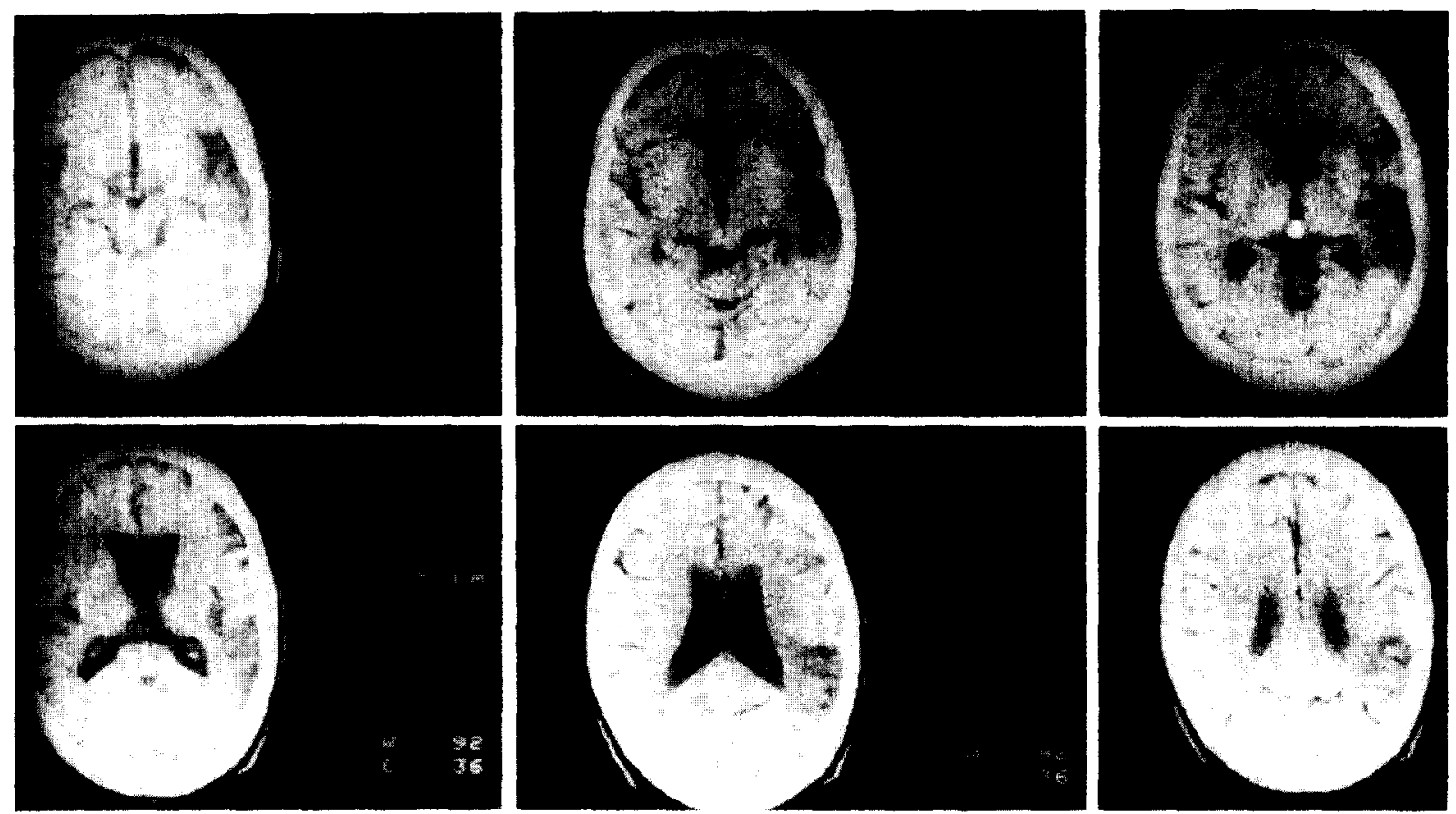

Fig. 4. CT scans of patient 2 demonstrating a left temporo-parietal lesion.

hearing loss and severe receptive-expressive aphasia and dyspraxia. Middle-latency auditory evoked responses recorded from this patient are illustrated in Fig. 5. With right ear stimulation, a well-defined response was noted at the vertex. The response recorded over the right hemisphere was slightly reduced with respect to the vertex responses as expected; the response recorded over the left hemisphere was markedly reduced when compared to the right hemisphere response. With left ear stimulation the responses recorded at vertex and over the right hemisphere were both well defined and nearly identical to responses elicited by right ear stimulation and recorded at the same electrode locations. The response recorded over the left hemisphere was markedly reduced both with respect to right hemisphere, left ear stimulation and to left hemisphere, right ear stimulation. With left ear stimulation, no response was evident at the electrode placed below the sylvian fissure over the left temporal lobe (T3). With right ear stimulation an early positive peak was evident at the left temporal electrode which was earlier than the Pa peaks recorded at the other 3 electrode locations and in fact coincided with the latency of $\mathrm{Na}$. This peak may have originated

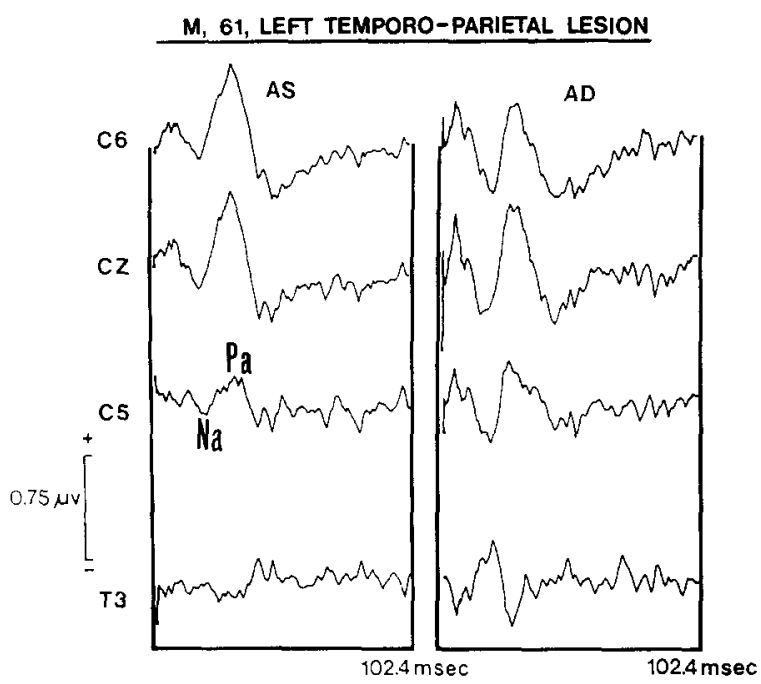

Fig. 5. Coronal distribution of MLR for patient 2 illustrating a reduction of the $\mathrm{Na}-\mathrm{Pa}$ amplitude over the left hemisphere (C5 and $T 3$ ). 
in the post-auricular muscle. An inspection of Fig. 1 , illustrating the coronal distribution of the MLR in a neurologically intact subject, reveals the presence of an identical peak at T3 especially with left ear stimulation (AS), partially blending in with $\mathrm{Pa}$.

\section{Patient 3 - right-sided frontal lesion}

A 21-year-old male sustained a right frontal subdural hematoma following a motor vehicle accident (Fig. 6). Speech-language and psychology examinations revealed impaired cognitive and comprehension abilities. An audiological evaluation indicated a slight high frequency hearing loss bilaterally. The ABR was unremarkable. Fig. 7 illustrates a normal coronal distribution of the MLR in this patient.

\section{Patient 4 - right anterior temporal lobectomy}

A 24-year-old female patient underwent a right anterior temporal lobectomy for seizure control. The extent of the removal was $6 \mathrm{~cm}$ along the sylvian fissure and $7 \mathrm{~cm}$ along the floor of the middle fossa. The patient's left temporal lobe seizures were only partially controlled by anticonvulsant medication. The MLRs recorded from this patient are illustrated in Fig. 8. The responses and the distribution appear essentially normal with the

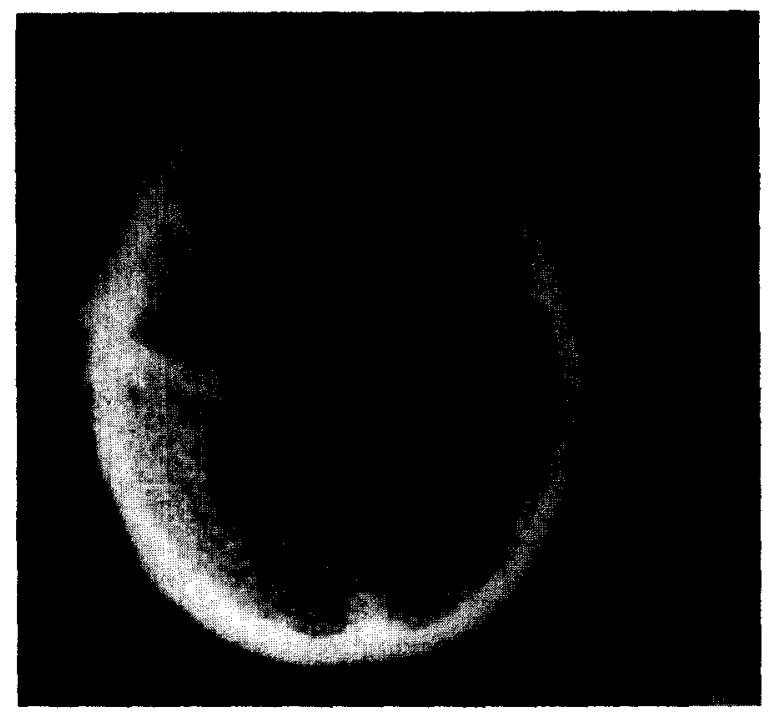

Fig. 6. CT scan of patient 3 demonstrating a right frontal subdural hematoma.

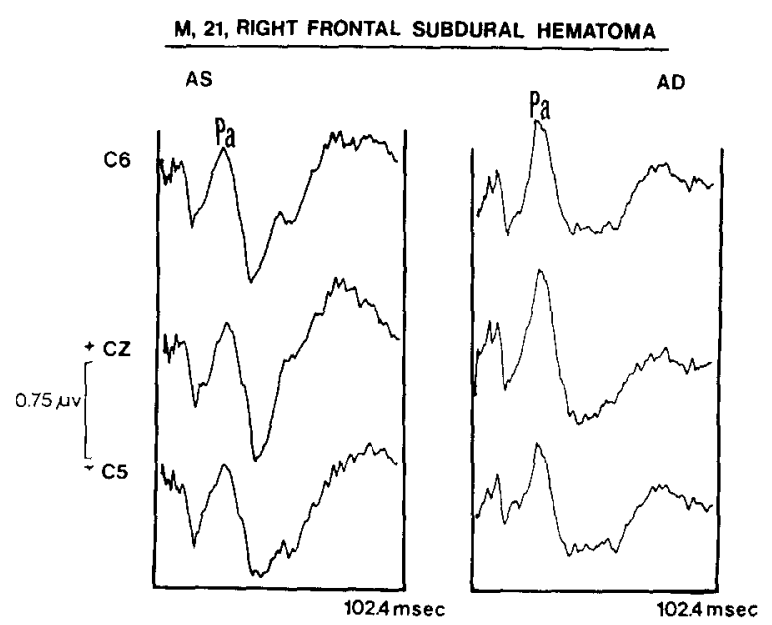

Fig. 7. Normal coronal distribution of MLR for patient 3.

exception of a reduction in $\mathrm{Pa}$ amplitude over the left unoperated hemisphere with left ear stimulation by comparison to the right hemisphere or to right ear stimulation. However, it is of note that the response over the right, operated side was within normal limits.

The information contained in the case studies may be summarized as follows. Lesions affecting the posterior half or two-thirds of the temporal lobe tended to compromise the integrity of the $\mathrm{Na}-\mathrm{Pa}$ complex recorded over the involved hemisphere. The superior temporal gyrus was affected in all such cases with an involvement of Brodmann's area 41 in the majority of patients. In cortical lesions that did not include the temporal

\section{F, 24, RIGHT ANTERIOR TEMPORAL LOBECTOMY MLR, CLICKS, $60 \mathrm{~dB} \mathrm{HL}$}

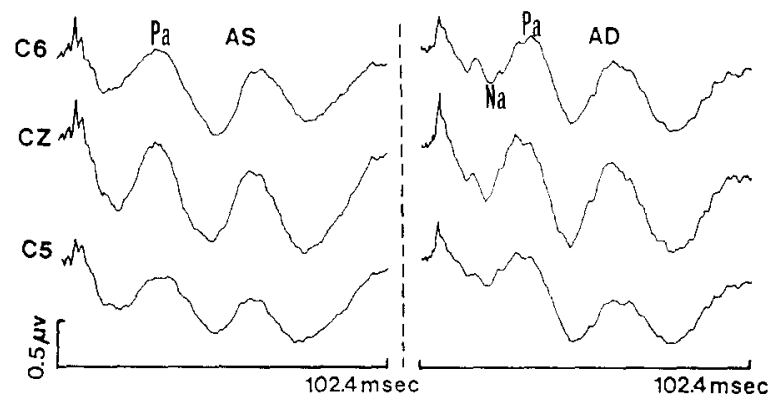

Fig. 8. Coronal distribution of MLR in patient 4 . 
lobes, the amplitude, configuration and the coronal distribution of the Na-Pa complex was intact. A unilateral anterior temporal lobectomy for seizure control left the $\mathrm{Na}-\mathrm{Pa}$ complex uncompromised. The vertex-recorded $\mathrm{Na}-\mathrm{Pa}$ complex appeared intact in all 4 patients with unilateral temporal lobe lesions. However, its amplitude rarely exceeded the amplitude of the Na-Pa complex recorded over the intact hemisphere.

Table $\mathrm{V}$ lists 10 brain structures most commonly affected in our 11 temporal lobe patients. The temporal gyri (superior, middle and inferior) were subdivided into their anterior and posterior aspects. Since as shown in Table I most of our patients sustained their lesions as a result of an infarction (most often middle cerebral artery), the damage was seldom limited to the temporal lobes. In the majority of cases studied, the extent of temporal lobe lesions was limited to their posterior aspects. Brodmann's areas 41 and 42 are considered to make up the auditory receptive cortex. These cortical areas are located in the middle third of the superior temporal gyrus on the superior aspect of the temporal operculum (area 41) and partially on the lateral surface (area 42) (Gado et al. 1979). Among all structures listed, the most common site of lesion was the posterior half of the superior temporal gyrus followed by area 41 . In $72 \%$ of our cases the posterior portion of the middle temporal gyrus was affected as well. In only $27 \%$ of our patients was there involvement of the inferior temporal gyrus. The insula was affected in about half of our patients. It is noteworthy that in $90 \%$ of our patients the post-central, supra-marginal and angular gyri were also involved. Two of the patients studied by us are not included in Table V. These patients, one of whom is described along with the case studies (case no. 5), had unilateral anterior temporal lobectomies for the relief of seizure disorders. In both, the extent of removal was $6-7 \mathrm{~cm}$ along the sylvian fissure and 6-7 cm along the floor of the middle fossa and the $\mathrm{Na}-\mathrm{Pa}$ amplitude distribution was not affected. Brodmann's area 42 was affected in 7 patients. The Na-Pa complex was absent in three of those. In the remaining 4 the Na-Pa peak-topeak amplitude was reduced over the involved hemisphere (for example case no. 1, Figs. 2 and 3).

\section{Discussion}

The results of this study are in general in good agreement with those reported by Kraus et al. (1982). We demonstrated a reduction of the $\mathrm{Na}-\mathrm{Pa}$ peak to-peak amplitude or its near-absence over the involved hemisphere in patients with lesions involving the posterior aspect of the temporal

\section{TABLE $V$}

Temporal lobe patients.

\begin{tabular}{|c|c|c|c|c|c|c|c|c|c|c|c|c|c|}
\hline & & \multicolumn{11}{|c|}{ Patient no. } & \multirow{2}{*}{$\begin{array}{l}\text { Area involved } \\
\text { in } \% \text { patients }(\%)\end{array}$} \\
\hline & & 1 & 2 & 3 & 4 & 5 & 6 & 7 & 8 & 9 & 10 & 11 & \\
\hline \multirow[t]{2}{*}{ Superior temporal g. } & A & $\mathrm{x}$ & & $X$ & & & & $x$ & & $\mathrm{X}$ & $X$ & & 45 \\
\hline & $\mathrm{P}$ & $\mathrm{x}$ & $\mathrm{X}$ & $\mathrm{x}$ & $X$ & $X$ & $\mathrm{X}$ & $\mathrm{X}$ & $\mathrm{X}$ & $\mathrm{X}$ & $\mathrm{X}$ & $\mathrm{x}$ & 100 \\
\hline Brodmann's area 41 & & $\mathrm{x}$ & $\mathrm{x}$ & $\mathrm{X}$ & $\mathrm{X}$ & $\mathrm{X}$ & $\mathrm{X}$ & $\mathrm{X}$ & $\mathrm{X}$ & $\mathrm{X}$ & & $\mathrm{x}$ & 90 \\
\hline Brodmann's area 42 & & $\mathrm{x}$ & & & $\mathrm{X}$ & $\mathrm{X}$ & $\mathrm{X}$ & $\mathrm{X}$ & & $\mathrm{X}$ & & $\mathrm{x}$ & 63 \\
\hline \multirow[t]{2}{*}{ Middle temporal g. } & A & $\mathrm{X}$ & & & & & & & & $\mathrm{X}$ & & & 18 \\
\hline & $\mathrm{P}$ & $\mathrm{X}$ & $X$ & & $x$ & $\mathrm{X}$ & & $\mathrm{x}$ & $\mathrm{X}$ & $\mathrm{x}$ & & $\mathrm{X}$ & 72 \\
\hline \multirow[t]{2}{*}{ Inferior temporal g. } & A & $\mathrm{X}$ & & & & & & $\mathrm{X}$ & & $\mathrm{x}$ & & & 27 \\
\hline & $\mathrm{P}$ & $\mathrm{X}$ & & & & & & $\mathrm{X}$ & & $\mathrm{x}$ & & & 27 \\
\hline Insula area & & & $\mathrm{X}$ & $\mathrm{X}$ & $\mathrm{X}$ & $\mathrm{x}$ & & & & $\mathrm{X}$ & & $\mathrm{X}$ & 54 \\
\hline Precentral g. & & & & & $\mathrm{X}$ & $\mathrm{X}$ & & & $\mathrm{X}$ & & & & 27 \\
\hline Postcentral g. & & $\mathrm{X}$ & & $\mathrm{X}$ & $\mathrm{X}$ & $\mathrm{X}$ & $\mathrm{X}$ & $\mathrm{X}$ & $\mathrm{X}$ & $\mathrm{X}$ & $\mathrm{X}$ & $X$ & 90 \\
\hline Supramarginal g. & & $\mathrm{X}$ & & $\mathrm{X}$ & $\mathrm{X}$ & $\mathrm{X}$ & $\mathrm{X}$ & $\mathrm{X}$ & $x$ & $\mathrm{X}$ & $x$ & $\mathrm{X}$ & 90 \\
\hline Angular g. & & $\mathrm{x}$ & & $\mathrm{X}$ & $\mathrm{X}$ & $\mathrm{X}$ & $\mathrm{X}$ & $\mathrm{x}$ & $\mathrm{X}$ & $x$ & $\mathrm{x}$ & $\mathrm{X}$ & 90 \\
\hline Inferior frontal g. & & & & & $X$ & $X$ & $\mathrm{X}$ & & & $\mathrm{X}$ & & & 36 \\
\hline
\end{tabular}


lobe. Our amplitude measurements and statistical analyses demonstrated a similar reduction of the absolute (baseline-to-peak) amplitude of $\mathrm{Pa}$ over the involved hemisphere. The amplitude of $\mathrm{Na}$ was not reduced in the temporal lobe lesion patient group. Therefore, the reduction of the $\mathrm{Na}-\mathrm{Pa}$ amplitude in cases with temporal lobe lesions appears to be mostly a function of the reduction of $\mathrm{Pa}$. As indicated in Tables II, III and IV, $\mathrm{Na}$ and $\mathrm{Pa}$ latencies were not affected in either of the patient groups.

In 2 cases following unilateral anterior temporal lobectomies, the MLR was intact over the involved hemisphere. As shown in Table $\mathrm{V}$, the posterior portion of the superior temporal gyrus was involved in all the other temporal lobe patients. That area includes the auditory cortex which in primates and in humans is buried in the sylvian fissure on its inner superior surface (Neff et al. 1975; Gado et al. 1979). However, in a high percentage of our cases with temporal lobe involvement, there were lesions affecting the frontal and parietal lobes as well. This of course is due to the fact that most of our patients had sustained cerebral vascular accidents involving the middle cerebral artery and the pattern of lesions reflects the distribution of the middle cerebral artery.

The cortical branches of the middle cerebral artery supply widespread areas of the frontal, parietal and temporal lobes including the auditory area. As shown in Table $\mathrm{V}$, next to the superior temporal gyrus, the 3 most common sites of involvement were the post-central, supra-marginal and angular gyri of the parietal lobe. The postcentral gyrus which is bounded by the central and post-central sulci receives somatic sensory input. The angular and the supra-marginal gyri are subdivisions of the inferior parietal lobule which lies inferior to the intra-parietal sulcus and posterior to the inferior portion of the post-central sulcus. Lesions of the angular gyrus are associated with an impairment of reading and writing abilities (Ross and Geschwind 1983). If one accepts the functions assigned to the parietal lobe, that leaves the temporal lobe and especially the posterior half or middle third of the superior temporal gyrus to account for the generation of the $\mathrm{Pa}$.

Lee et al. (1984) recorded auditory evoked re- sponses from the posterior banks of the sylvian fissure by means of subdural electrodes in humans. Following an early positive peak attributed to the brain-stem response complex $(6 \mathrm{msec})$ the response consisted of a succession of positivenegative-positive peaks with the major positive peak having a latency of $28.8 \pm 0.3 \mathrm{msec}$. These responses were larger for contralateral stimulation than ipsilateral stimulation at recording sites located on the superior temporal gyrus or above the sylvian fissure, near the motor cortex. The subdural electrode locations at which maximal response amplitudes were obtained by Lee et al. (1984) were adjacent to the halfway point along the sylvian fissure parallel to its posterior half. These sites coincide with lesion sites in patients with reduced $\mathrm{Pa}$ amplitudes presented in this study. Coincidentally, these locations were not involved in the two patients who underwent anterior temporal lobectomies that spared $\mathrm{Pa}$ and hence the $\mathrm{Na}-\mathrm{Pa}$ complex of the MLR. The Na-Pa amplitude asymmetry between the intact and the involved hemispheres appeared more pronounced when stimulating the ear ipsilateral to the involved hemisphere. However, the results of the statistical analyses did not support the significance of this phenomenon.

Based on the data presented in this paper, the following conclusions may be reached. As previously demonstrated by Kraus et al. (1982) the vertex recorded Na-Pa complex of the MLR appears to be the result of bilateral generators located in close proximity to the sylvian fissures. The distribution of the lesions and the presence of intact MLRs in two cases of anterior temporal lobectomy further narrow down the source of the neural generators of the Na-Pa complex to the posterior aspect of the superior temporal gyrus and the sylvian fissure. The importance of the temporal lobes in the generation of the $\mathrm{Na}-\mathrm{Pa}$ complex is further indicated by the presence of intact MLRs in patients with traumatic and vascular brain lesions that did not involve the temporal lobes. Furthermore, our measurements and statistical analyses identified $\mathrm{Pa}$ as the component most affected by lesions of the posterior aspect of the superior temporal gyrus. The amplitude of $\mathrm{Na}$ was not affected, therefore, we may cautiously con- 
clude that its generator may be separate from that of $\mathrm{Pa}$.

The clinical implications of our results are two-fold. First, the middle-latency auditory evoked responses may provide us with an objective means to follow patients who have sustained traumatic or vascular unilateral or bilateral temporal lobe lesions. Secondly, middle-latency auditory responses may be used to evaluate the status of the temporal lobe or lobes in patients in whom there is a suspicion of temporal lobe involvement based on various other clinical measures but in whom the lesion is such that present imaging techniques do not disclose the presence of a recognizable lesion or structural anomaly.

\section{Résumé}

Effets de lésions corticales sur les réponses évoquées auditives à moyenne latence

Les réponses évoquées auditives à latence moyenne ont été enregistrées simultanément par 3 ou 4 électrodes situées dans le plan frontal chez 5 sujets normaux, 11 patients avec lésion du lobe temporal et 5 patients dont la lésion corticale épargnait le lobe temporal. Chez les patients présentant une lésion unilatérale du lobe temporal, l'amplitude de $\mathrm{Pa}$ et celle du complexe $\mathrm{Na}-\mathrm{Pa}$ était diminuée au-dessus de l'hémisphère lésé mais restait inchangée au-dessus de l'hémisphère contralatéral. Aucune asymmétrie dans ces réponses n'a été constatée chez les patients dont la lésion corticale épargnait le lobe temporal et chez les deux patients avec lobectomie temporale antérieure unilatérale. La latence de l'onde $\mathrm{V}$ de la réponse auditive du tronc cérébral était normale pour la majorité des patients, quel que soit la localisation de leur lésion corticale.

\section{References}

Brazier, M.A.B. The Neurophysiological Background of Anesthesia. Thomas. Springfield, IL, 1972: 82-117.

Celesia, G.G., Broughton, R.J., Rasmussen, T.H. and Branch, C. Auditory evoked responses from the exposed human cortex. Electroenceph. clin. Neurophysiol., 1968, 24: 458-466.
Gado, M., Hanaway, J. and Frank, R. Functional anatomy of the cerebral cortex by computed tomography. J. Comput. Assist. Tomogr, 1979, 3:1-19.

Geisler, C.D., Frishkopf, L.S. and Brown, R.M. The 'Early' Response to Clicks in Awake Subjects. Quart. Progr. Rep. Res. Lab. of Electronics, M.I.T., Cambridge. MA, 1957: 144-148

Harker, L.A., Hosick, E., Voots, R.J. and Mendel, M.I. Influence of succinylcholine on middle component auditory evoked potentials. Arch. Otolaryng., 1977, 103: 133-137.

Heath, R.G. and Galbraith, G.C. Sensory evoked responses recorded simultaneously from human cortex and scalp. Nature (Lond.), 1966, 212: 1535-1537.

Jasper, H.H. The ten-twenty electrode system of the International Federation. Electroenceph. clin. Neurophysiol., 1958. 10: $371-375$

Kileny, P. Auditory evoked middle latency responses: current issues. Sem. Hear., 1983, 4: 403-413.

Kileny, P., Dobson, D. and Gelfand. E.T. Middle latency auditory evoked responses during open-heart surgery with hypothermia. Electroenceph. clin. Neurophysiol.. 1983, 55: 268-276.

Kraus, N., Özdamar, Ö., Hier, D. and Stein. L. Auditory middle latency responses (MLRs) in patients with cortical lesions. Electroenceph. clin. Neurophysiol., 1982, 54: 275-287.

Lee. Y.S., Lueders, H., Dinner, D.S., Lesser, R.P., Hahn, J. and Klem, G. Recording of auditory evoked potentials in man using chronic subdural electrodes. Brain, 1984. 107: $115-131$

Neff, W.D., Diamond, I.T, and Cassaday, J.H. Behavioral studies of auditory diserimination: central nervous system. In: W.D. Keidel and W.D. Neff (Eds.). Handbook of Sensory Physiology. Auditory System, Vol. 5. No. 2. Springer, Berlin, 1975: 307-400.

Özdamar, Ö. and Kraus, N. Auditory middle-latency responses in humans. Audiology, 1983, 13: 195-204.

Özdamar, Ö.. Kraus, N. and Curry, F. Auditory brainstem and middle latency responses in a patient with cortical deafness. Electroenceph. clin. Neurophysiol., 1982, 53: 224-230.

Parving, A., Solomon, G., Elberling, C., Larsen. B. and Lassen, N.A. Middle components of the auditory cvoked response in bilateral temporal lobe lesions. Scand. Audiol., 1980, 9: 161-167.

Peters, J.G. and Mendel, M.I. Early components of the averaged electroencephalic response to monaural and binaural stimulation. Audiology, 1974, 13: 195-204.

Picton, T.W. Hillyard, S.A., Kraus, H.I. and Galambos, R. Human auditory evoked potentials. I. Evaluation of components. Electroenceph. clin. Neurophysiol., 1974, 36: 179-190.

Pulletti, F. and Celesia, G.G. Functional properties of the primary cortical auditory area in man. Neurosurgery. 1970 . 32: 244-247.

Ross, E.D. and Geschwind, N. Disorders of higher brain functions. In: R.N. Rosenberg (Ed.), The Clinical Neurosciences. Neurology, Vol. 2. Churchill Livingstone. New York, 1983: 777-798 
Scherg, M. Distortion of the middle latency auditory response produced by analog filtering. Scand. Audiol., 1982, 11: $57-60$.

Sprague, B.H. and Thornton, A.R. Clinical utility and limitations of middle-latency auditory evoked potentials. ASHA, 1982, 24: 736.
Woods, D.L. and Clayworth, C.C. Click spatial position influences middle latency auditory evoked potentials (MAEPs) in humans. Electroenceph. clin. Neurophysiol., 1985, 60: 122-129. 